\title{
Nursing students' attitudes toward patient-centred care in the United Kingdom
}

\author{
Annette M. J inks ${ }^{1}$, Angela Cotton ${ }^{1}$, Philip Murphy², Jennifer Kirton ${ }^{1}$ \\ 1. Evidence-based Practice Research Centre, Faculty of Health and Social Care, Edge Hill University, Ormskirk, UK. 2. \\ Psychology Department, Faculty of Art and Sciences, Edge Hill University, Ormskirk, UK \\ Correspondence: Jennifer A Kirton. Address: Edge Hill University, Faculty of Health \& Social Care, Edge Hill University, \\ L39 4QP, UK. Email: Jennifer.kirton@edgehill.ac.uk.
}

Received: December 20, 2012

Accepted: February 20, $2013 \quad$ Online Published: May 27, 2013

DOI : $10.5430 /$ jnep.v3n12p116

URL: http://dx.doi.org/10.5430/jnep.v3n12p116

\section{Abstract}

Background: Respecting the uniqueness of each individual as part of person-centred approach is central to the provision of high quality nursing care. Valuing people as individuals with different needs and aspirations are attitudes to care-giving that student nurses need to develop. There is however, a scarcity of literature which focuses on assessment of student nurses’ patient-centred attitudes.

Aim: To examine patient-centred attitudes among pre-registration nursing students.

Design: A validated survey tool developed by Rolfe was used to measure the patient centred attitudes of nursing students in a U.K. University.

Methods: The patient-centred attitudes of 149 student nurses were measured using a Patient-Centred Multi-Choice Questionnaire. Standard descriptive analyses were performed.

Results: Female student nurses ( $\mathrm{n}=119)$ undertaking undergraduate pre-registration nurse education, 20- to 29- years-old and in their third year of study dominated the sample group. The mean Patient-Centred Multi-Choice Questionnaire scores for the majority of the sample groups fell within the noticeably therapeutic attitude range. Those that scored highest within the noticeably therapeutic attitude range were males, under 20- years-old, second-year students and students studying children's health.

Conclusion: The relatively high levels of patient-centred attitudes which were evidenced, particularly the results from the male students, is reassuring. The conclusions drawn have implications for nurse recruitment strategies, assessment of prospective student patient-centred attitudes and the teaching, learning and assessment strategies deployed by nurse educators.

\section{Key words}

Student nurse, Patient-centred attitudes

\section{Introduction}

A patient-centred approach is thought to be central to the provision of high quality nursing care. Imparting this approach through education programmes that nurture the development of professional caring attitudes and behaviour is one of the 
key concerns of the study undertaken. The aim of this study is to examine the patient-centred attitudes of a sample of undergraduate pre-registration student nurses (SNs). Patient-centred attitudes were measured using the Patient-Centred Multi-Choice Questionnaire (PMQX) developed by Rolfe in $1993^{[1]}$.

\section{Background}

What constitutes patient-centred care may be the subject of ambiguity with some researchers describing the approach as one where health professionals 'try to enter the patient's world to see the illness through the patient's eyes'(p1087) ${ }^{[2]}$. Important to this approach is the use of good inter-personal relationship skills which authors, such as Reynolds ${ }^{[3]}$, describe as being the "soft skills" needed by health professionals. These types of values may be traced back to a number of major philosophical traditions of the Nineteenth Century including that of the person-centred approach to counselling that was developed by the American psychologist Carl Rogers ${ }^{[4]}$. Rogers' humanistic model of counselling practice moved away from the old doctor/patient model of the counsellor as an expert, authority figure who knew everything about the client to one where understanding the uniqueness of the individual and a professionals' responses to a patients' wants needs, and preferences are central. Rogers ${ }^{[4]}$ gives the core attributes needed by counsellors in order to bring about therapeutic change as being: empathy which encompasses experiencing an accurate, empathic understanding of the client's awareness of his own experience, unconditional positive regard which means the counsellor is accepting and non-judgemental of the client, and congruence which Rogers believes is where the counsellor, in the confines of the therapeutic relationship, is consistent and genuine. Rolfe ${ }^{[1]}$ when developing the PMQX, which was used to measure student nurses' patient-centred attitudes in the present study, employed Rogers's attitudes of empathy, respect and genuineness as underpinning concepts. The importance of such concepts to nursing practice remains constant through time as review of the literature reveals. For example, they are similar to those identified by Mead and Bowers ${ }^{[2]}$ who have conducted a review of the empirical literature concerning patient-centredness. Whilst Mead and Bower's ${ }^{[2]}$ work focuses on the delivery of high quality care by physicians, nevertheless it is possible to distil some comparisons to Roger's constructs and patient-centred nursing care. For example, Mead and Bowers' themes of 'the patient as person' and 'therapeutic alliances' relate directly to Roger's concepts of empathy and congruence.

Other researchers which focus on high quality nursing care underwrite the continuing importance of Rogers' ${ }^{\text {[4] }}$ values in understanding the uniqueness of the individual and person-centred approaches as being central to all nursing actions. For example, Bouthillette ${ }^{[5]}$ in a Canadian qualitative study found oncology patients valued eight attributes of effective nursing care which in turn related to general outcomes, such as a sense of wellbeing. A sense of wellbeing is described by Bouthillette ${ }^{[5]}$ as feeling more comfortable and at ease and includes the components of trust, optimism, and authenticity or freedom to be themselves. Many of these values directly relate to those of Rogers, ${ }^{\text {[4] }}$ attributes for person-centred care. Similarly, Murphy ${ }^{[6]}$ in a study conducted in Ireland, investigates what the components of good nursing care are for older people and identifies that individualised care which focuses on patient choice and involvement in decision-making is essential to patient-centred approaches to care.

Imparting patient-centred skills to student nurses is of key concern to nurse educators ${ }^{[7-9]}$. For example, Skaalvik et al. ${ }^{[7]}$ in a Norwegian study describes how student nurses learn person-centred approaches to care of patients with Alzheimer's disease through clinical experiences. Skaalvik et al. ${ }^{[7]}$ relate how caring for patients with Alzheimer's disease may cause frustration, sadness, fear and increasing lack of empathy. Some of the students studied by Skaalvik et al. ${ }^{[7]}$ experienced limited learning regarding person-centred approaches to caring for these same patients. However, the information obtained in the study was used to develop strategies as to how student learning could be improved. Furthermore Christiaens et al. ${ }^{[8]}$ conducted a study in the United States (U.S.) which examines the advice expert holistic nurses give to nursing students regarding the theory and practice of holistic nursing. Examples of the most common advice from the experts to the nursing students include the importance of person-centred care, empathy and touch.

There is however a scarcity of literature focusing on the development of patient-centred attitudes in more formal academic situations such as University studies. Jinks ${ }^{[9]}$ purports nurse educators in the United Kingdom (U.K.) may act as role 
models for student nurses and through imitation of caring professional teaching behaviours student nurses may deliver care following the model displayed by educators when caring for patients. McLafferty ${ }^{[10]}$ investigated nurse educators’ and student nurses' attitudes toward older people in the UK which reflects Jinks ${ }^{[9]}$ hypothesis. McLafferty ${ }^{[10]}$ compared the attitudes of student nurses to those of nurse teachers towards working with hospitalised older adults. The results indicated nurse teachers were more positive than the student nurses studied on a number of items concerning care of elderly people. McLafferty concludes it is the responsibility of nurse educators along with clinical staff to dispel the negative stereotypes that student nurses bring into nursing.

Examination of the literature concerning measurement of patient-centred attitudes of healthcare students revealed there is a relative abundance of literature concerning physicians. Mead and Bower ${ }^{[2]}$ in a review of the methodological approaches to the measurement of doctors' patient-centredness identifies there are a number of approaches to measurement and a variety of measurement scales available for use. There are also a number of studies looking at the measurement of medical student's patient-centredness. For example, Haidet et al. ${ }^{[1]}$ describes a study in the U.S. which examines the attitudes of medical students towards patient-centred care. In a survey of 673 students in the first, third, and fourth years of medical school and using the Patient-Practitioner Orientation Scale (PPOS) ${ }^{[12]}$, it was found those studying in the earlier years of medical school had significantly higher patient-centred attitudes whereas students in the later years of medical training displayed attitudes that were more doctor-centred and paternalistic.

Little literature was found concerning the measurement of patient-centred attitudes of student nurses. One of the very few studies identified is conducted by Rolfe ${ }^{[13]}$. Using the same scale used in the present study, Rolfe found in a survey of 267 U.K. student nurses that high levels of patient-centredness at commencement of the course were associated with age, marital status and radicalism. Positive changes in patient-centredness during the course of the programme were associated with variables such as class size and a student-centred climate. Jinks ${ }^{[9]}$ also reports on use of the PMQX and found in a national sample of 192 pre-registration students that the majority had patient-centred attitude scores that fell within the noticeably therapeutic attitude range. Significantly higher scores were associated with those in the later stages of the University programme and the males in the sample.

It may be concluded whilst Rogers ${ }^{[4]}$ concepts of person-centredness may be considered by some to be dated, they are still highly relevant to the provision of high quality nursing care today. Using Rogers' concepts of valuing people as individuals with different needs and aspirations is an important approach to care-giving; nursing students need to learn this wherever the setting. This study is designed is explore present-day student nurse patient-centred attitudes to care.

\section{Materials \& methods}

\subsection{Design}

A validated survey tool developed by Rolfe ${ }^{[1]}$ was used to measure the patient-centred attitudes of nursing students in a U.K. University.

\subsection{Setting \& sample}

149 student nurses from a single U.K. University.

\subsection{I nstrument}

The patient-centred attitudes of 149 student nurses were measured using the PMQX which is an instrument developed by Rolfe ${ }^{[1]}$ to measure attitudes of empathy, genuineness and respect ${ }^{[4]}$. The questionnaire consisted of ten statements covering the three attitudes, made to a nurse by a patient with each statement being followed by five possible replies. The replies reflect different levels of attitude being assessed from highly subtractive (this is the least person-centred response - 
level 1) to highly additive (the most person-centred response - level 5). For example, statement number three on the PMQX has a patient saying to a nurse 'I feel strange when I enter a room with other people in it. Everyone looks at me.' This is followed by five replies, designed in this instance to measure the empathic response of the nurse. The level 1 (least patient-centred/highly subtractive) response in this case is 'Try in those situations to keep eye contact with people. I'm sure you'll soon find that you are feeling better'. The level 5 (most patient centred/highly additive) response on the other hand is 'So if there are already other people in the room when you go in, you feel awkward and embarrassed. I also detect a sense of unworthiness, as you feel you have no right to be there'. The respondent is required to select one response to each statement which results in a score for each of the three attitudes and estimates of an overall patient-centredness score being made.

Rolfe ${ }^{[1]}$ categorised the total PMQX scores achieved by the participant as representing from significantly untherapeutic attitudes to significantly therapeutic attitudes. An overview of the scoring system that was developed by Rolfe is given in Table 1.

Table 1. PMQX scoring

\begin{tabular}{ll}
\hline PMQX Score & Categorisation \\
\hline $10-19$ & Significantly untherapeutic attitude \\
$20-29$ & Noticeably untherapeutic attitude \\
30 & Minimally therapeutic attitude \\
$31-40$ & Noticeably therapeutic attitude \\
$41-50$ & Significantly therapeutic attitude \\
\hline
\end{tabular}

\subsection{Validity and reliability}

Rolfe ${ }^{[1]}$ tested the validity and reliability of the PMQX by undertaking a number of studies. To summarise Rolfe ${ }^{[1]}$ validated the PMQX against the Barrett-Lennard Relationship Inventory ${ }^{[14]}$ which is a similar but is longer and more time consuming to administer. With data collected from a sample of 94 nursing students Rolfe found correlations between the average PMQX and BLRI scores were high $(r=0.3, P=0.005)$. Test-retest measures of reliability were also undertaken with a further group of 87 students and a test-retest reliability coefficient was found to be 0.86 . Piloting the instrument with a further 327 students Rolfe found the PMQX scores of this sample ranged from a minimum of 25 which is below the minimally therapeutic level of 30 to a maximum of 47 which is considered to be significantly therapeutic. The mean was 37.775 with approximately two-thirds of the students having scores ranging from 33 to 42.

For this study, a small pilot study was undertaken in September 2011 by the present authors with a focus on presentation and acceptability of the PMQX. A small sample of student nurses who were not part of the main sample group but had similar characteristics were asked to comment on the usability of the PMQX. The sample was asked questions concerning ease of understanding the clinical scenarios and their applicability. No adverse comments were made and therefore only minor changes concerning typographical errors and presentation were carried out.

\subsection{Sample details}

The setting of the study was a University in the North West of England that offers a range of healthcare programmes including undergraduate, pre-registration nurse educational programmes. The total population of nursing undergraduates in the University in any given academic year is approximately 1100 . A convenience sample of student nurses who were undertaking pre-registration undergraduate courses in adult, child, mental health and learning disability nursing were approached to take part in the study.

\subsection{Data collection}

Having gained permission from senior educational managers to access the nursing students a time for researcher access was arranged which was usually before or after the students had completed a programmed teaching session. Following 
initial explanations concerning the purpose of the study, reassurances were given that participation was entirely voluntary and any student not wishing to complete the PMQX could leave without suffering any academic or personal penalties. However, most students decided to participate in the study. Participating students viewed the experience as an interesting opportunity to know how to calculate their patient-centred scores. Maximum and minimum times for completion of the PMQX were found to be around 20 minutes to one hour. Those who completed the questionnaire were asked to leave quietly so as not to disturb the remainder of the group. The students were asked to keep a note of responses so feedback on how to score their PMQX responses could be given.

\subsection{Ethics}

University ethical approval was obtained to undertake the study. The principles of informed consent were applied with information about the study being distributed two weeks before the data collection took place (October 2011). Written consent was not obtained as the voluntary nature that governed completion of the PMQX was taken as implying consent. Permission to use the PMQX for the study was acquired from the author of the instrument ${ }^{[1]}$.

Data were stored in accordance with the University ethical guidance; all data is to be stored for 10 years and to be kept in secure environment. Paper based records will be destroyed in accordance with University confidential waste policy.

\subsection{Data analysis}

Data were entered into SPSS 18.0 (PASW) for analysis, with standard descriptive analyses being performed for all the variables. As the total caring scores constituted the sum of ordinal ratings, nonparametric procedures were used to analyse this variable. Total caring scores were compared with regard to gender, year of study and branch of nursing. Differences between the two respondent groups on demographic and training variables were compared using standard descriptive analyses.

\section{Findings}

One hundred and fifty four students were approached to take part in the study. There were five incomplete questionnaires that were discarded. Therefore the final data set contained the results from 149 respondents. Generally it was found mental health, female student nurses (119, 80.0\%), aged between 21 to 29 years (77, 51.7\%) and who were in their third year of study (82, 55.0\%) dominated the sample group. The least represented were child branch (20,13.4\%), male students (30, $20.0 \%)$, those aged under 20 years $(25,16.8 \%)$, and who were in their second year of study $(24,16.1 \%)$. These findings are displayed in table 2.

Table 2. Sample details

\begin{tabular}{llll}
\hline Characteristics & & Frequency & Percentage \\
\hline Gender & Male & 30 & $20 \%$ \\
Age & Female & 119 & $80 \%$ \\
& Under 20years & 25 & $16.8 \%$ \\
& $21-29 y e a r s$ & 77 & $51.7 \%$ \\
& $30-39$ years & 27 & $18.1 \%$ \\
Year of study & Over 40 years & 20 & $13.4 \%$ \\
& $1^{\text {st }}$ Year & 43 & $28.9 \%$ \\
Branch & $2^{\text {nd }}$ Year & 24 & $16.1 \%$ \\
& $3^{\text {rd }}$ Year & 82 & $55 \%$ \\
& Adult & 36 & $24.2 \%$ \\
& Mental Health & 50 & $33.6 \%$ \\
& Child & 20 & $13.4 \%$ \\
\end{tabular}


The findings indicate that the range of the students' PMQX scores were 26 to 48 and the mean for the whole sample was 38.83 there were a small number of PMQX scores at the lower end of the distribution curve indicating that is few students had low PMQX scores that were only minimally therapeutic ( $n=8$ had PMQX scores of under 30). Many more of the sample had high PMQX scores that were therapeutic ( $\mathrm{n}=85$ had PMQX scores of over 40). However the mean PMQX scores for the total sample were 38.83 which is what Rolf (1993) identifies as being within the noticeably therapeutic attitude range. Those that scored higher within the noticeably therapeutic attitude range were males (mean PMQX scores = 36.45), those under 20 years old (mean PMQX scores $=37$ ), second year students (mean PMQX scores = 36.96) and child branch students (mean PMQX scores $=37.55$ ). Participants receiving lower scores but still within the noticeably therapeutic attitude range were females $(n=119)$ (mean PMQX scores $=34.39)$, those aged 30 to 39 years old $(n=27)$ (mean PMQX scores 34.74), first year students $(n=43)$ (mean PMQX scores $=35.51)$ and learning disability students $(n=$ 43) (mean PMQX scores = 35.28). Table 3 shows the mean and standard deviations for total caring scores across genders, age categories, year of study, and branch of nursing.

Table 3. PMQX scores

\begin{tabular}{|c|c|c|c|}
\hline Characteristics & & Mean & SD \\
\hline \multirow[t]{2}{*}{ Gender } & Male & 36.45 & 3.6 \\
\hline & Female & 34.33 & 4.7 \\
\hline \multirow[t]{4}{*}{ Age } & Under 20years & 37.00 & 3.6 \\
\hline & 21-29years & 36.03 & 3.9 \\
\hline & 30-39 years & 34.74 & 4.0 \\
\hline & Over 40 years & 36.55 & 4.0 \\
\hline \multirow[t]{3}{*}{ Year of study } & $1^{\text {st }}$ Year & 35.51 & 4.1 \\
\hline & $2^{\text {nd }}$ Year & 36.96 & 2.6 \\
\hline & $3^{\text {rd }}$ Year & 36.02 & 4.1 \\
\hline \multirow[t]{4}{*}{ Branch } & Adult & 35.94 & 4.2 \\
\hline & Mental Health & 36.12 & 3.9 \\
\hline & Child & 37.55 & 3.5 \\
\hline & Learning Disability & 35.28 & 3.8 \\
\hline Overall & & 38.83 & 3.8 \\
\hline
\end{tabular}

A Mann-Whitney analysis was conducted with results of $\mathrm{U}$ score of $1,323.5$ ( $p<.028$, two tailed) for gender between groups.

\section{Discussion}

The results gathered from this study provide some interesting findings. The higher PMQX scores (demonstrating a more patient centred attitude) of the males in the sample provides some evidence that caring behaviours are not innate. Also caring behaviours may be learnt during professional socialisation processes which are an inherent part of nurse educational programmes. This point is made by Jinks and Bradley ${ }^{[15]}$ who found the tendency towards beliefs in gender and nursing stereotypes had diminished through time in participants enrolled in the study. In a replicated attitude survey of newly recruited student nurses it was found that student nurse beliefs concerning an attitude statement that 'women are more affectionate and caring than men' (p125) appeared to have weakened over a ten year period. There is, however, evidence male nurses may exhibit caring behaviours differently than females, which may be associated with common male nurse stereotypes. It may be concluded that whilst men may exhibit care behaviours differently to females the albeit limited evidence presented in this study is that males are more patient-centred than females.

Whilst no findings related to other extraneous variables were identified in the present study it is possible to compare the findings to those of Rolf ${ }^{[12]}$ and Jinks ${ }^{[9]}$ who have undertaken similar studies. Such comparisons help to put into context the findings of the present study. For example, Rolfe had a range of PMQX scores being 25 to 47, the mean being 37.775 
and the standard deviation 4.413. Jinks ${ }^{[9]}$ reports a similar range of PMQX scores to Rolfe, with scores being 26 to 47. However, the mean PMQX scores reported by Jinks are more than Rolfe's with the scores being 38.96. In the present study the range of the students PMQX is similar to both Rolfe and Jinks, however the mean PMQX scores of the students in the present study is higher than those reported by both Rolfe ${ }^{[12]}$ and Jinks ${ }^{[9]}$ which may indicate a slight trend in student nurse patient-centred scores have increased over time (Rolfe study in 1993, Jinks study 1997). This is a reassuring finding because it confirms that generally the majority of students display appropriate attitudes to care delivery expected in present nursing care.

Whilst Rolfe ${ }^{[12]}$ reports no significant findings related to other variables, Jinks ${ }^{[9]}$ does report third year students in the sample had significantly higher PMQX scores than those students enrolled in earlier programme years in their training. This leads Jinks to theorise the level of the programme of nurse training the students were enrolled on had a positive effect on the student nurse participants' patient centred attitudes. Whilst the same was not found in the present study it was found that second and third year students mean PMQX scores were higher than students enrolled in first year of studies. However it is acknowledged that further research is needed to confirm Jinks ${ }^{[9]}$ findings perhaps using a longitudinal cohort study approach.

The findings of the present study also need to be viewed in general context of the study's limitations. For example, whilst some of the characteristics of the sample used in the present study conform to what national profiles of pre-registration undergraduate cohorts of student nurses in the UK are reported as being some do not. The age range of the sample group as related earlier was found to be predominately 21-29 years old. As Buchan and Seccombe ${ }^{[17]}$ relate those aged 26 and over account for more than $40 \%$ of all applications for nurse education in the UK and represent $46 \%$ of all those accepted. However, this may be changing as in 2012, Buchan and Seccombe ${ }^{[17]}$ found increases in applicants to nurse education have mainly been associated with those aged under 25. Other characteristics of the sample do, however, differ. For example, there are more males in the present study than would be expected in this type of sample group. Buchan and Seccombe ${ }^{[17]}$ estimate about $92 \%$ of applicants to nurse education are women with men accounting for only one in 10 (11\%) of accepted applicants in the U.K. Again this feature of the student nurse population in the UK maybe changing as Buchan and Seccombe ${ }^{[17]}$ relate the number of male recruits has dropped from being nearly 15\% of applicants in 1999. Similarly adult nursing students are under- represented in the present study. Again Buchan and Seccombe ${ }^{[17]}$ estimate national commissioning numbers for adult nursing students are around $69 \%$ of total recruits, whereas mental health student numbers are $17 \%$ and learning disability $3 \%$. It may be concluded the sample in the present study is therefore skewed with more males, mental health and learning disability students being included than would be expected on a national basis. Whilst this does not invalidate the findings of the present study it does support the view that further studies with larger sample groups are needed.

Other limitations of the present study relate to use of the PMQX. For example, more widespread use of the PMQX would give greater reassurances of its reliability and validity. The fact the instrument was developed nearly two decades ago calls into question the relevance of some of the questionnaire items in the climate of healthcare provision today. However, as related earlier the small pilot study conducted directly prior to the present study did not identify that the PMQX clinical scenarios as being out-dated. Also, other similar instruments have been used over time without significant amendments and the development work undertaken by Rolfe ${ }^{[1]}$ when originally constructing the instrument was extensive. Other limitations of the study that have been referred to previously relate to the convenience nature of the sample group and its relative small sample size which call into question the generalisability of the study's findings. Nevertheless it is thought in view of current interest in raising the standards of patient care in the UK and the importance placed on patient-centred approaches this study is timely and relevant to current healthcare outcomes.

Whilst the limitations of this study are acknowledged nevertheless our findings have a number of implications for nurse education. For example, Murphy et al ${ }^{[8]}$ relate how caring is a central value in nursing practice and acquiring caring competences is a crucial component of nurse education programmes. However, Chiovitti ${ }^{[19]}$ describes the concept of 
caring as intangible and abstract and even an invisible component of nursing practice. Nonetheless inherent in all caring behaviours is the ability to treat people as unique individuals though the adoption of patient-centred approaches. Despite the importance of students acquiring patient-centred skills assessment of such skills at recruitment and during the course of a nurse education programme there are few if any tools available to measure caring attributes. Whilst more research around the use of the PMQX is needed it is believed there are many potential uses of the instrument in educational practice. As related earlier the students studied found feedback on the individual PMQX scores useful and interesting. Used in non-punitive reflective type sessions the PMQX offers interesting opportunities to explore how patient-centred approaches maybe translated into practice-related scenarios and provides a means for nurse educators to role model such behaviours.

\section{Conclusions}

Whilst the various aspects of the study's limitations may mitigate some of the findings of the study nonetheless it is believed this study has many positive and useful features. Evidence indicating the recruited student participant's demonstrate high levels of patient-centred attitudes and this being particularly true for the male students is particularly reassuring. The Rogerian underpinnings of this study and humanistic beliefs are a direct contrast to the cult of individual that many social commentators see as pervaded both UK and the many others Western Nations' belief systems ${ }^{[20]}$. There is also some evidence that some care standards in the UK are unsatisfactory ${ }^{[21]}$. For example, findings of the recent report of the UK Care Quality Commission ${ }^{[21]}$ shows whilst there were many examples of high quality care observed during the CQC inspections on a few occasions poor standards of care were witnessed. Whilst this study only provides very limited evidence to inform such weighty debates there is no denying the University where the study was undertaken needs to be cognizant of the study's findings. Recruitment strategies at the University need a continued focus on assessment of candidates' patient-centred attitudes. Also, the introduction of educator-guided self-reflective activities for the students that include informed patient-centred care approaches needs further consideration.

\section{References}

[1] Rolfe G. The Patient-Centred Multi-Choice Questionnaire: developing an instrument for the measurement of patient-centredness in student nurses Journal of Advanced Nursing. 1993; 18: 120-1267. PMid:8429156 http://dx.doi.org/10.1046/j.1365-2648.1993.18010120.x

[2] Mead N \& Bower P. Patient-centredness: a conceptual framework and review of the empirical literature Social Science \& Medicine. 2000; 51: 1087-1110. http://dx.doi.org/10.1016/S0277-9536(00)00098-8

[3] Reynolds A. Patient-centred care Radiologic Technology. 2009; 81(2): 133-47. PMid:19901351

[4] Rogers C. The Necessary and Sufficient Conditions for Therapeutic Personality Change. Journal of Consulting Psychology. 1957; 21: 97-103. http://dx.doi.org/10.1037/h0045357

[5] Bouthillette F. Oncology patients’ perceptions of quality nursing care Evidence Based Nursing. 2001; 4(1): 3.

[6] Murphy K. A qualitative study explaining nurses' perceptions of quality care for older people in long-term care settings in Ireland. Journal of Clinical Nursing. 2007; 16 (3): 477-85. PMid:17335523 http://dx.doi.org/10.1111/j.1365-2702.2005.01526.x

[7] Skaalvik MW, Norman HK \& Henrikson N. Student experiences in learning person-centred care of patients with Alzheimer's disease as perceived by nursing students and supervising nurses. Journal of Clinical Nursing. 2010; 19(17/18): 2639-48. PMid:20920084 http://dx.doi.org/10.1111/j.1365-2702.2010.03190.x

[8] Christiaens G, Abegglen JA, \& Gardner A. Expert holistic nurses' advice to nursing students. Journal of Holistic Nursing. 2010; 28(3): 201-8. PMid:20585104 http://dx.doi.org/10.1177/0898010110369176

[9] Jinks AM. Caring for patients, caring for student nurses, Ashgate, Aldershot. 1997.

[10] McLafferty E. A comparison of nurse teachers and student nurses attitudes towards hospitalised older adults Nurse Education Today. 2005; 25(6): 472-9. PMid:15993516 http://dx.doi.org/10.1016/j.nedt.2005.04.007

[11] Haidet P, Dains JE, Paterniti DA, Hechtel L, Chang T, Tseng E, Rogers JC. Medical student attitudes toward the doctor-patient relationship Medical Education. 2002; 36(6): 568-574. PMid:12047673 http://dx.doi.org/10.1046/j.1365-2923.2002.01233.x

[12] Krupat E, Rosenkranz SL, Yeager CM, Barnard K, Putnam SM, Inui TS. The practice orientations of physicians and patients: the effect of doctor-patient congruence on satisfaction. Patient Educ Couns. 2000; 39: 49-59. http://dx.doi.org/10.1016/S0738-3991(99)00090-7

Published by Sciedu Press 
[13] Rolfe G. Some factors associated with change in patient-centredness of student nurses during the Common Foundation Programme in Nursing. International Journal of Nursing Studies. 1994; 31(5): 421-36. http://dx.doi.org/10.1016/0020-7489(94)90013-2

[14] Barrett-Lennard GT. Dimensions of a therapist response as causal factors in therapeutic change Psychological Monographs. 1962; 76: 43. http://dx.doi.org/10.1037/h0093918

[15] Jinks and Bradley. Angel, handmaiden, battle-axe of whore? A study that examines changes in newly recruited student nurses' attitudes to gender and nursing stereotypes Nurse Education Today. 2004; 24: 121-127. PMid:14769456 http://dx.doi.org/10.1016/j.nedt.2003.10.011

[16] Evans JA. Cautious caregivers: gender stereotypes and sexualisation of men nurses’ touch Journal of Advanced Nursing. 2002; 40(4): 441-8. PMid:12421403 http://dx.doi.org/10.1046/j.1365-2648.2002.02392.x

[17] Buchan J \& Seccombe I. Past trends, future imperfect? A review of the UK nursing labour market in 2004 to 2005, RCN, London

[18] Murphy F, Jones S, Edwards M, James J \& Mayer A. The impact of nurse education on the caring behaviours of nursing students Nurse Education Today. 2009; 29: 254- 264. PMid:18945526 http://dx.doi.org/10.1016/j.nedt.2008.08.016

[19] Chiovitti RF. Nurses' meaning of caring with patients in acute psychiatric hospital settings: a grounded theory study International Journal of Nursing Studies. 2008; 45(2): 203-23. PMid:17049355 http://dx.doi.org/10.1016/j.ijnurstu.2006.08.018

[20] Gerhardt S. 2010. The Selfish Society, Simon \& Schuster, London

[21] Buchan J \& Seccombe I. 2012. Overstretched. Under-resourced. The UK nursing labour market review 2012, RCN, London Care Quality Commission (2011) State of Care Report 2010/2011. Available from:

http://www.cqc.org.uk/public/reports-surveys-and-reviews/reports/state-care-report-2010/11/quality-and-safety 